\title{
Tsunami Scattering and Earthquake Faults in the Deep Pacific Ocean
}

\author{
Harold O. Mofjeld \\ NOAA, Pacific Marine Environmental Laboratory • Seattle, Washington USA
}

\author{
Christina Massell Symons, Peter Lonsdale \\ Scripps Institution of Oceanography · La Jolla, California USA
}

\author{
Frank I. González, Vasily V. Titov \\ NOAA, Pacific Marine Environmental Laboratory • Seattle, Washington USA
}

\section{Introduction}

Tectonic processes in the deep ocean occur over an immerse range of temporal and spatial scales. The shortest in time are from seconds to minutes during which earthquakes and landslides occur. The recurrence interval between earthquakes, submarine landslides, and volcanic eruptions may be tens, hundreds, or thousands of years. At the far end of the range are the tens of millions of years over which oceanic plates form at the spreading centers and drift, sometimes thousands of kilometers with speeds of a few centimeters per year, to the subduction zones. It is also over these long time scales that chains of volcanic islands and seamounts form and over even longer time scales that major asteroids may impact the Earth. These processes create a host of smaller-scale geological features, including rift valleys, earthquake fault scarps, submarine landslide deposits, and abyssal hills, which cover vast areas of the ocean floor. Using a wide variety of methods, scientists are developing a better understanding of these geological features and the processes that create them.

When a submarine earthquake occurs on the continental shelf or slope, one consequence can be the generation of a tsunami that then propagates across the ocean and impacts distant shorelines as well as the nearby coast. These earthquakes can generate landslides that in turn increase the overall amplitude of the resulting tsunamis. This apparently occurred during the deadly 1946 Alaska Tsunami in Hawaii, which led to the creation of the U.S. Tsunami Warning Centers. The recent 1998 Papua New Guinea earthquake and tsunami killed over 2,000 people. Ship surveys carried out soon after this event revealed a large, newly formed landslide scarp (cliff) immediately offshore of the tsunami inundation zone. A volumetric analysis of the slide and tsunami modeling has shown that the landslide contributed substantially to the tsunami.
Eruptions of island and submarine volcanoes can also create tsunamis and are of great interest in understanding how volcanic islands and seamounts form. Examples of recent volcanic events that have or could generate tsunamis in the Caribbean Sea are the eruptions of the submarine Kick'em Jenny Volcano near Grenada and the Soufriere Volcano on Montserrat. Other examples are the eruptions and landslides from Vulcano, and other islands near Italy, and the worrisome movement of the South Flank on the Island of Hawaii.

In this paper, we will discuss two very different projects involving geological features in the Pacific Ocean (Figure 1). The first focuses on the effects of seamounts and other wave scatterers on tsunamis propagating across the Pacific, while the second is a study of deep-water earthquake faults near the PeruChile and Tonga-Kermadec Trenches in the South Pacific. What is common about these ongoing projects is that they both rely on accurate, fine-detail bathymetry over large areas of the deep ocean. The bathymetry is needed to establish the existence of geological features in a region and then to quantify their spatial distributions, sizes, orientations, shapes, and ranges of depth. Limitations in the accuracy and spatial resolution of the bathymetry also limit what can be learned about the features and their effects of oceanographic processes. In turn, this leads to a set of requirements for new bathymetric data that are needed in order for the research to advance.

\section{Trans-Oceanic Tsunamis}

Tsunamis are long gravity waves that are generated in the ocean by abrupt geophysical events such as earthquakes, landslides, or volcanic eruptions. Sometimes these processes work in conjunction to enhance the amplitudes of the tsunamis. There is also evidence that huge tsunamis have occurred in the 


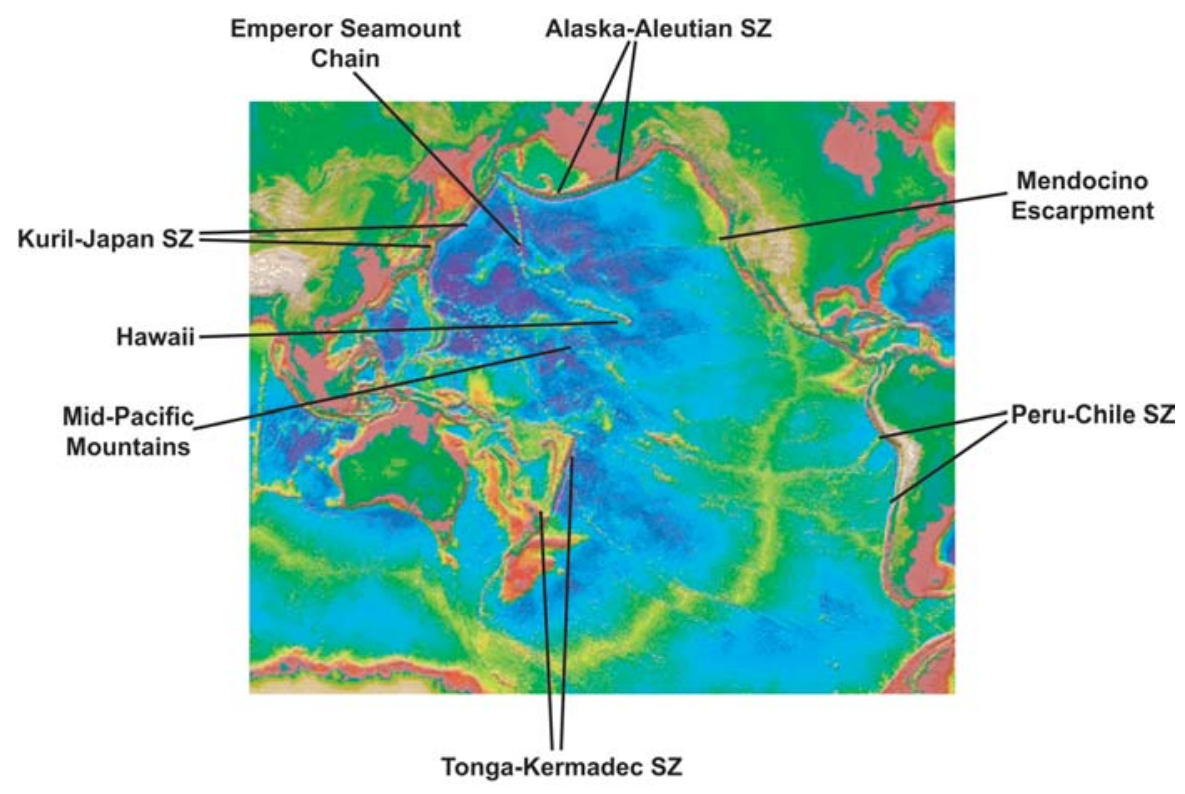

Figure 1. The Pacific Ocean basin is rimmed by plate tectonic subduction zones and their associated ocean trenches and chains of volcanic arcs, popularly known as the "ring of fire". The largest earthquakes in the world are generated in subduction zones. Submarine earthquakes, eruptions, and landslides generate tsunamis, which can bring catastrophic flooding to coastal areas in a matter of minute or hours. The bathymetric features identified here play a role in generating, scattering, or focusing these waves, as discussed in the text.

\section{Table 1}

Representative tsunami phase speeds $\mathrm{c}=\sqrt{\mathrm{gH}}$ based on long gravity waves where $g$ is the acceleration of gravity $\left(\mathrm{g}=9.8 \mathrm{~m} / \mathrm{s}^{2}\right)$ and $\mathrm{H}$ is the local water depth.

\begin{tabular}{c|c|c}
$\begin{array}{c}\text { Depth } \\
(\mathrm{m})\end{array}$ & $\begin{array}{c}\text { Phase Speed } \\
(\mathrm{m} / \mathrm{s})\end{array}$ & $(\mathrm{km} / \mathrm{hr})$ \\
\hline 50 & 22 & 80 \\
\hline 100 & 31 & 113 \\
\hline 500 & 70 & 252 \\
\hline 1000 & 99 & 356 \\
\hline 2000 & 140 & 504 \\
\hline 3000 & 171 & 617 \\
\hline 4000 & 198 & 713 \\
\hline 5000 & 221 & 797 \\
\hline 6000 & 242 & 873 \\
\hline
\end{tabular}

geological past when asteroids struck the Earth. Tsunamis are called long waves because their wavelengths (the distances between successive wave crests) are much longer than the water depth.

Tsunamis have such long wavelengths (tens to hundreds of kilometers in the deep ocean) because the abrupt bottom movements that generated them have large horizontal scales. Smaller-amplitude source events tend to have smaller spatial scales, but their tsunamis are usually significant only near the source. However, the ground movements associated with major subduction earthquakes can have finer-scale structure. Localized areas of stronger ground movement, called asperities, often occur. Indeed, model simulations of tsunamis are used to estimate the source distribution of the tsunamis by tuning the simulations to tsunami observations from coastal tide gauges and offshore pressure gauges.

Multiple reflections and partial wave trapping, especially near the source, produce an extended wave train of many waves even though the original source was a single impulse. The later waves in a tsunami form very complicated patterns in which it is difficult to determine the relationship of a later wave to the initial source. Hence, only the observations of the first few waves at a site are used for comparison with model simulations and estimation of the earthquake source parameters.

The phase speed at which tsunami waves move is given by the long wave formula. As shown in Table 1, these waves travel across the deep ocean at hundreds of kilometers per hour. Hence it takes a number of hours for a tsunami to traverse a major ocean, whereas the same tsunami impacts the local coast within a few minutes. The period $\mathrm{T}$ of a tsunami (the time elapsed between the passage of two successive wave crests) is determined by the wavelength $\lambda$ and the phase speed $c$ through the dispersion relation $\lambda=\mathrm{cT}$. The typical periods of trans-oceanic tsunamis range from about 2 to 90 minutes. 


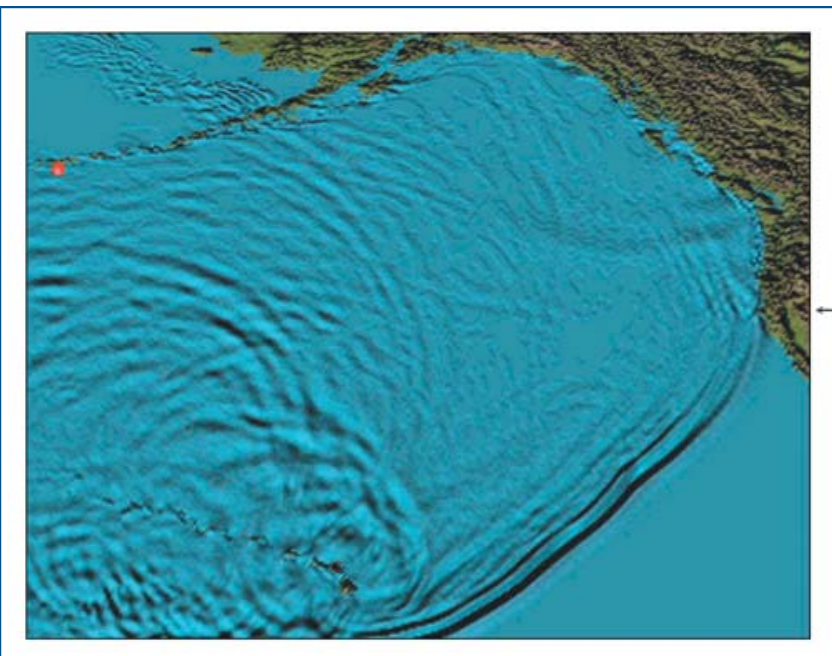

Figure 2. Model simulation of the 1996 Andreanof Island tsunami showing the instantaneous sea level pattern 5 hours and 35 minute after the earthquake, which was located at the red dot, in the Aleutian Islands of Alaska. The land areas of Western North America are in the upper right; the Hawaiian Islands in the lower left. Note that the tsunami propagates as a train of waves, not just a single impulse, and that this train is refracted and scattered in several directions by ocean bottom features. Of particular importance to coastal California, Oregon, and Washington states is the scattering pattern indicated by the arrow (middle of the right hand edge), where a bathymetric ridge known as the Mendocino Escarpment acts as a wave guide and directs energy at nearby coastal cities. Taken with permission from Mofjeld et al. (2001).
If the oceans were of constant depth, the first waves of trans-oceanic tsunamis would arrive at an impact site by a great circle route on the globe. However, broad-scale variations of the water level cause the tsunami waves to refract with a tendency for the wave crests to turn toward shallower water. Using wave ray-tracing methods and coarse bathymetric grids, travel-time maps were constructed by tsunami warning centers to predict when tsunamis would arrive at impact sites from the major source areas around the Pacific Ocean that have a history of producing dangerous tsunamis.

\section{Tsunami Wave Scattering}

In the late 1980s, the NOAA/Tsunami Research Program at the Pacific Marine Environmental Laboratory began a program to develop numerical models with very high spatial resolution. This ongoing R\&D effort is part of the National Tsunami Hazard Mitigation Program and has two main goals. The first is to create accurate tsunami inundation maps for U.S. coastal communities bordering the Pacific Ocean, to be used by emergency managers in developing evacuation plans.

The second goal is to provide the U.S. Tsunami Warning Centers with an improved tsunami forecasting system, based on real-time reporting bottom pressure gauges (tsunameters) deployed in the deep Pacific and a rapid-access database of tsunami model simulations with unit-amplitude sources in the tsunami source areas around the Pacific Region. Called SIFT for Short-

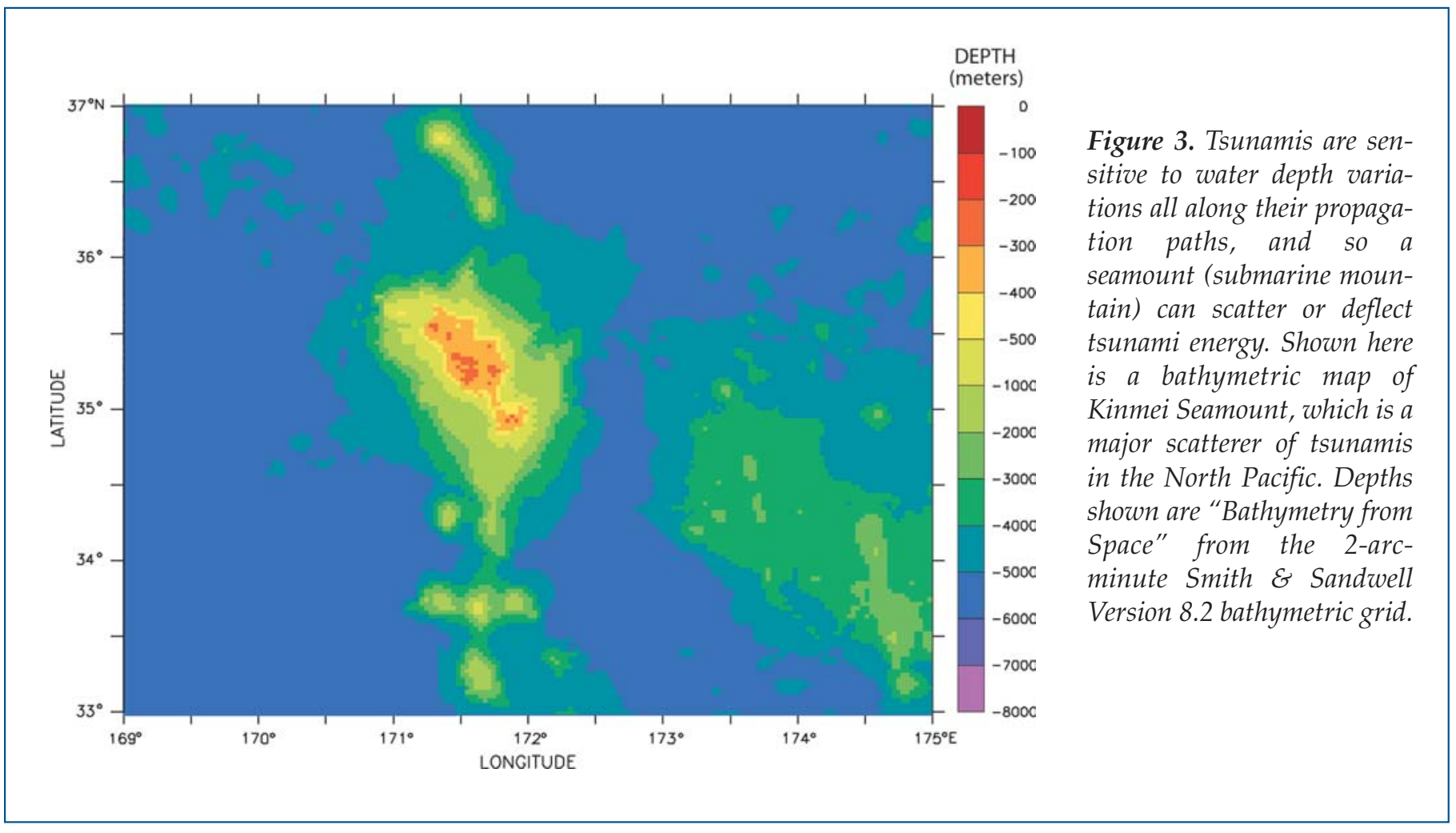


Box 1

Tsunami Scattering Index

The tsunami scattering index $S$ is used to identify submarine features in the open ocean that interact significantly with tsunami waves.

$S=1-T_{\min }$

Where $T_{\min }$ is the minimum transmissivity (ratio of the transmitted wave amplitude to the incident wave's) for a tsunami wave propagating across a straight submarine ridge with rectangular cross-section; the minimum occurs when the phase shift of the wave across the ridge is $90^{\circ}$.

Analytic theory (Mofjeld et al., 2000) shows that

$\mathrm{T}_{\min }=2 \varepsilon /\left(1+\varepsilon^{2}\right)$

Where $e={ }_{\sqrt{ }} \mathrm{H}_{1} / \mathrm{H}_{0}$ is the ratio of the minimum depth $\mathrm{H}_{1}$ of a topographic feature to the depth $\mathrm{H}_{0}$ of the surrounding region.

The theory also shows that the scattering index is indicative of scattering potential by ridges of different cross-sections and by seamounts.

term Inundation Forecast for Tsunamis, the Pacificwide simulations are tuned to the tsunameter data and then provide open seaward boundary conditions for inundation models of coastal communities to be run in real-time. A SIFT prototype was made available to the Tsunami Warning Centers in February of 2004.

In the late 1980s and 1990s, high-resolution bathymetric grids became available that enabled numerical models to simulate trans-Pacific tsunamis much more accurately as they propagated across the Pacific. Using the MOST (Method of Splitting Tsunamis) finite difference model that he developed, Vasily Titov and coworkers in the NOAA/Tsunami Research Program began to simulate and analyze the numerous tsunamis in the 1990s soon after they occurred. The model used the high-resolution Smith/Sandwell bathymetric grid developed from a combination of altimetric data from satellites and ship-track observations.

From the model simulations, it became immediately apparent that small-scale topographic features in the open ocean were having a major effect on tsunamis as they propagate across some regions of the Pacific Ocean. Figure 2 shows an example of tsunami wave scattering in the North Pacific that occurred in the model waves from the 1996 Andreanof Islands Earthquake in the western Aleutians after they propagated southward and struck the Emperor Seamount Chain, the Northwest Hawaiian Ridge and the Hawaiian Islands. Also contributing to the scattering are the Musician Seamounts and Hess Rise northwest of Hawaii, and probably the Shatsky Rise to the west of the Emperor Seamount Chain. In simulations of several trans-Pacific tsunamis, concentric rings of tsunami waves were seen to be emanating from Kinmei Seamount (Figure 3) at the southern end of the Emperor Seamount Chain. Apparently a very effective scatterer, the Seamount has a broad shallow top. Scattering by mid-ocean topographic features affects not only the amplitudes of tsunamis that have passed through the scattering regions but also the directionality of the tsunamis and the duration of the tsunami wavetrain in time.

Near the northern California Coast in Figure 2 is a small wave pattern generated as the Mendocino Escarpment interacts with the tsunami waves. The effects of the Escarpment on tsunami waves may contribute to the anomalously large tsunami amplitudes that often occur at Crescent City located along the coast to the north. Linear features like escarpments and ridges are likely to act as tsunami waveguides when the waves are incident at oblique angles over a critical value. For instance, Shunichi Koshimura, Fumihiko Imamura, and Nobuo Shuto found that the South Honshu Ridge in the Western Pacific acted as a waveguide, concentrating wave energy from the south and directing it toward Japan. They were able to model this effect as seen at island tide gages during the 1996 Irian Jaya tsunami. MOST model simulations by Vasily Titov for the 1994 Shikotan Tsunami, originating near Northern Japan, show that the Hawaiian Ridge also acts as a waveguide for tsunamis propagating from the west and thereby increases the amplitudes of tsunamis in Hawaii.

\section{Tsunami Scattering Index}

Missing from the tsunami wave patterns in Figure 2 is any apparent scattering by rough bottom topography that lies over large areas of the northeast Pacific, except from the seamount chains near the West Coast and the Mendocino escarpment. It is clear then that the depth of water over topographic features is critically important to the scattering process in which shallow features are much more effective at scattering tsunami waves while deep ones have little effect.

To better understand the effects of water depth on tsunami wave scattering, a theory was developed by Harold Mofjeld and co-workers in the NOAA/Tsunami Research Program based on long gravity waves interacting with topographic features with simple shapes. This work led to the development of a tsunami scattering index (Box 1) that is computed directly from a bathymetric grid. As the name implies, the index identifies the features in an ocean that are likely to scatter tsunami waves significantly.

The tsunami scatter index was computed from the Smith/Sandwell bathymetric grid, which has a resolution of two nautical miles at the equator and then increases to one nautical mile at latitudes of $60^{\circ} \mathrm{N} / \mathrm{S}$. The regional water depths needed for comparison (Box 1 ) with the minimum depths of topographic features 


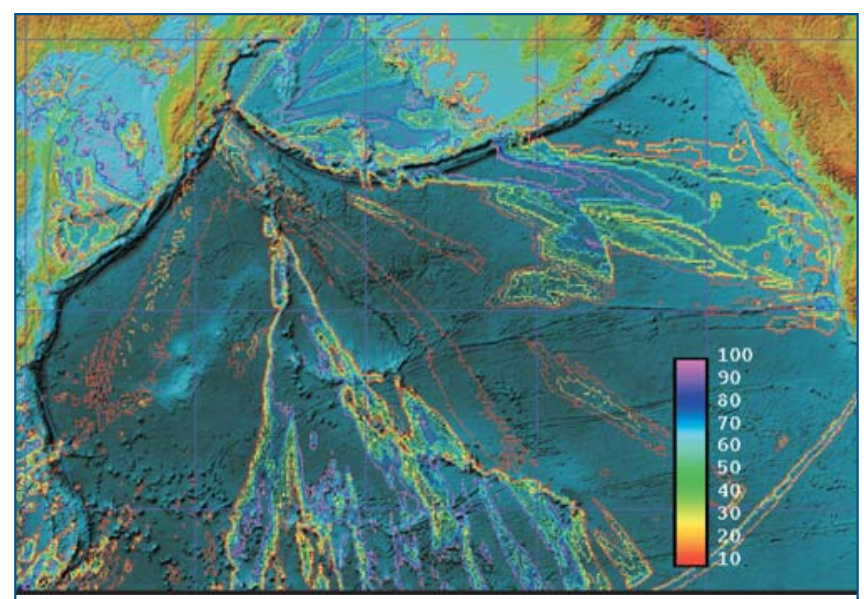

Figure 4. Bathymetry from Space has revealed sea floor topographic features that are important controls on the amplitude of tsunamis arriving in coastal areas. To demonstrate their importance, a model of tsunami propagation have been run in two forms, one using the most detailed bathymetry available, the other with the finescale features filtered out. Shown here are the differences in tsunami amplitudes in the North Pacific between the two cases of the 1997 Kamchatka tsunami, in which the amplitudes are found to differ by as much as 100\% or more.

were computed by low-pass filtering the bathymetric grid using wavelet methods to remove the smaller features such as seamounts and ridges. Basically, features that extend upward to within $500 \mathrm{~m}$ scatter significant tsunami energy. The influence of scattering can be seen in Figure 4 for the 1997 Kamchatka tsunami that shows that differences in model tsunami amplitudes when the fine-scale topographic features are, or are not, included in the bathymetric grid.

Like the model simulation of the 1996 Andreanof Island Tsunami (Figure 2), the scattering index (Figure 5) for the Pacific Ocean shows that the major scattering features in the North Pacific are the Emperor Seamount Chain, the Hawaiian Ridge and the Hawaiian Islands. Further, there is a lack of significant scatterers to the north and east of these except in eastern Gulf of Alaska. In contrast, there are a large number of scatterers in the Mid-Pacific Mountains, Polynesia, Micronesia, and the Izu-Bonin Ridge. This helps explain why historically, tsunami generated in the Southwestern Pacific have posed little danger to Hawaii. Farther south, bands of scatterers runs westward from South America toward Tonga, Australia, and New Zealand. Modeling efforts are underway to understand the influence of these features on tsunamis generated in the Peru-Chile Subduction Zone as the prototype SIFT forecasting system is expanded to the entire Pacific.

\section{Outer Rise and Slope Morphology}

Trench outer slopes are among the most dynamic sites of tectonic relief formation on Earth. Subducting lithosphere approaches a trench and in a matter of 100,000 years is subject to extreme plate-bending forces at the outer slope. Seafloor morphology remains relatively unchanged as it moves away from spreading ridges across the abyssal plain and towards subduction zones. As the lithosphere approaches the subduction zone it is subject to bending stresses and it first flexes up into an outer rise, then down into the trench (Figure $6 a, b)$. The result is an outer rise crest and outer slope morphology that characterizes most subduction zones. The amplitude of the outer rise crest may range from nonexistent to as large as $1300 \mathrm{~m}$. The outer slope averages $3^{\circ}$ to $8^{\circ}$.

The character and evolution of seafloor morphology at mid-ocean spreading ridges is well established. Large-scale features such as spreading ridges, fracture zones, and off-axis volcanoes are identified on the basis of their free-air gravity signature. Goff et al. (this issue) discuss the abyssal hill faults that dominate the smallscale component of the seafloor morphology. As Goff et al. explain, the current altimeter data is too noisy to identify all abyssal hill trends, however, their orientation can be deduced from their tectonic relationship with the larger-scale features. The orientation of abyssal hills plays a role in the response of the lithosphere as it bends in the outer rise region.

Plate-bending forces at the outer slope are great enough to break the surface, in many places scarring it with high-relief, bending-induced faults. Scarps can grow on the order of $50 \mathrm{~cm}$ per 100 years in vertical relief. Outer-slope faulting is classified as one of two categories-reactivated abyssal hill faults or new, bending-induced faults that crosscut the inherited abyssal hills (Figure 7a, b). As a general rule of thumb if the abyssal hills strike within $30^{\circ}$ of the axis of plate bending (and are thereby approximately parallel to the trench axis) they will rejuvenate. If the abyssal hills strike greater than $30^{\circ}$ to the bending axis new bending-induced faults will break the crust (Masson, 1991). Swath bathymetric surveys along the Peru-Chile Trench and the Tonga-Kermadec Trench (Massell, 2002) revealed unique patterns of faults at transitional angles within $30 \pm 5^{\circ}$.

Fault style in the outer slope region varies. Scarps of rejuvenated abyssal hills are observed to be on the order of 150-300 $\mathrm{m}$ in height and are primarily trenchfacing. They present a "step fault" morphology as adjacent blocks step down into the trench axis (Figure 6c). Their linear extent may approach $60-80 \mathrm{~km}$, a trait that reflects their original abyssal hill fault length. New, bending-induced faults develop 40-60 $\mathrm{km}$ from the trench axis as horst and graben pairs. Their scarp heights increase to as great as $1400 \mathrm{~m}$, averaging $800-1000 \mathrm{~m}$. New faults average $100 \mathrm{~km}$ in length (Figure $6 c$ and Figure $7 a, b$ ). 


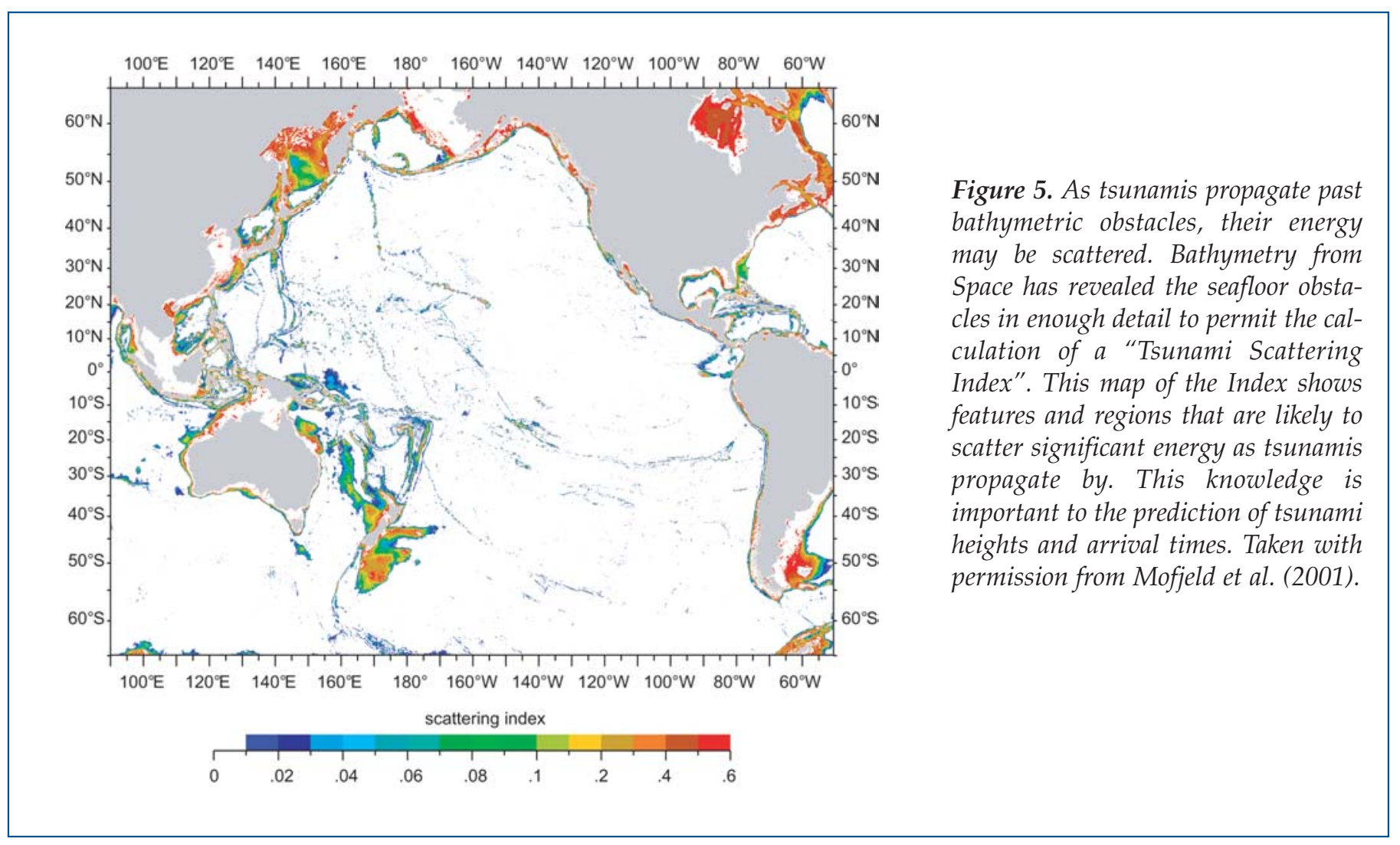

Large, anomalously oriented scarps are observed along some trench outer slopes and cannot be classified as reactivated abyssal hill faults or new, bendingaxis-parallel faults. In the Arica Bight region of the Peru-Chile Trench, where the trench axis changes orientation by nearly $60^{\circ}$, a series of sub-parallel scarps crosscut abyssal hills as well as the projected orientation of new faults. The large, anomalously oriented scarps measure $1300 \mathrm{~m}$ in height (Figure 6c). Detailed mapping revealed that the location of these scarps coincides with a volcano. Because of the large positive gravity anomaly attributed to the outer rise crest, the volcano was not predicted prior to swath mapping. The relationship of the scarp, the volcano and the large bend in the trench axis at the Arica Bight has not been established. An anomalously large scarp has also been identified at the northern end of the Tonga Trench. The map view trace of the plate boundary turns abruptly westward by $90^{\circ}$ and active scarps as high as 500-800 $\mathrm{m}$ extend $200 \mathrm{~km}$ from the outer rise region. These anomalous scarps may be the means by which the subducting lithosphere accommodates this very large change in plate boundary geometry and consequently may be characterized as areas of probable seismicity.

Faults adjacent to and crosscutting subducting seamounts are identified in swath bathymetric data. Although seamounts have been identified via their gravity signature along the Peru-Chile Trench and the Tonga Trench outer slopes, current altimeter data does not reveal the nature of the break-up of seamounts as they approach the trench axis across the outer slope. In places where the seamounts are not physically breaking up themselves, they serve as a crustal heterogeneity around which bending-induced faults on the outer slope must divert. The otherwise trench axis-parallel trends of the outer slope faults may bend by as much as $20-30^{\circ}$.

\section{Seismicity}

Seismic activity in a subducting slab can be characterized by predictable processes related to the bending of the lithosphere into a trench and beneath the overriding plate. Bending of the lithosphere puts the upper surface of the plate into tension, and the lower surface into compression, resulting in normal faults and thrust, or reverse faults, respectively. Outer rise earthquakes have traditionally been attributed to plate bending tensional stresses (Stauder, 1968; Chapple and Forsyth, 1979). However large, high-angle thrusting events $(\mathrm{mb}=5-7)$ have been recorded in the outer rise region where motion on the plane of contact between the overriding and subducting plate may result in low-angle thrust events (Christensen and Ruff, 1988; Mueller et al., 1996). Whether rupture associated with these events extends to the seafloor, rupturing the surface and expressing a thrust-fault morphology, is not well known.

Thrust blocks adjacent to the trench axis are identified on swath bathymetry as likely products of interplate compression. On some places seismic events likely to have been associated with these features have been recorded. In the Peru-Chile Trench between $18^{\circ} \mathrm{S}$ 
(a)

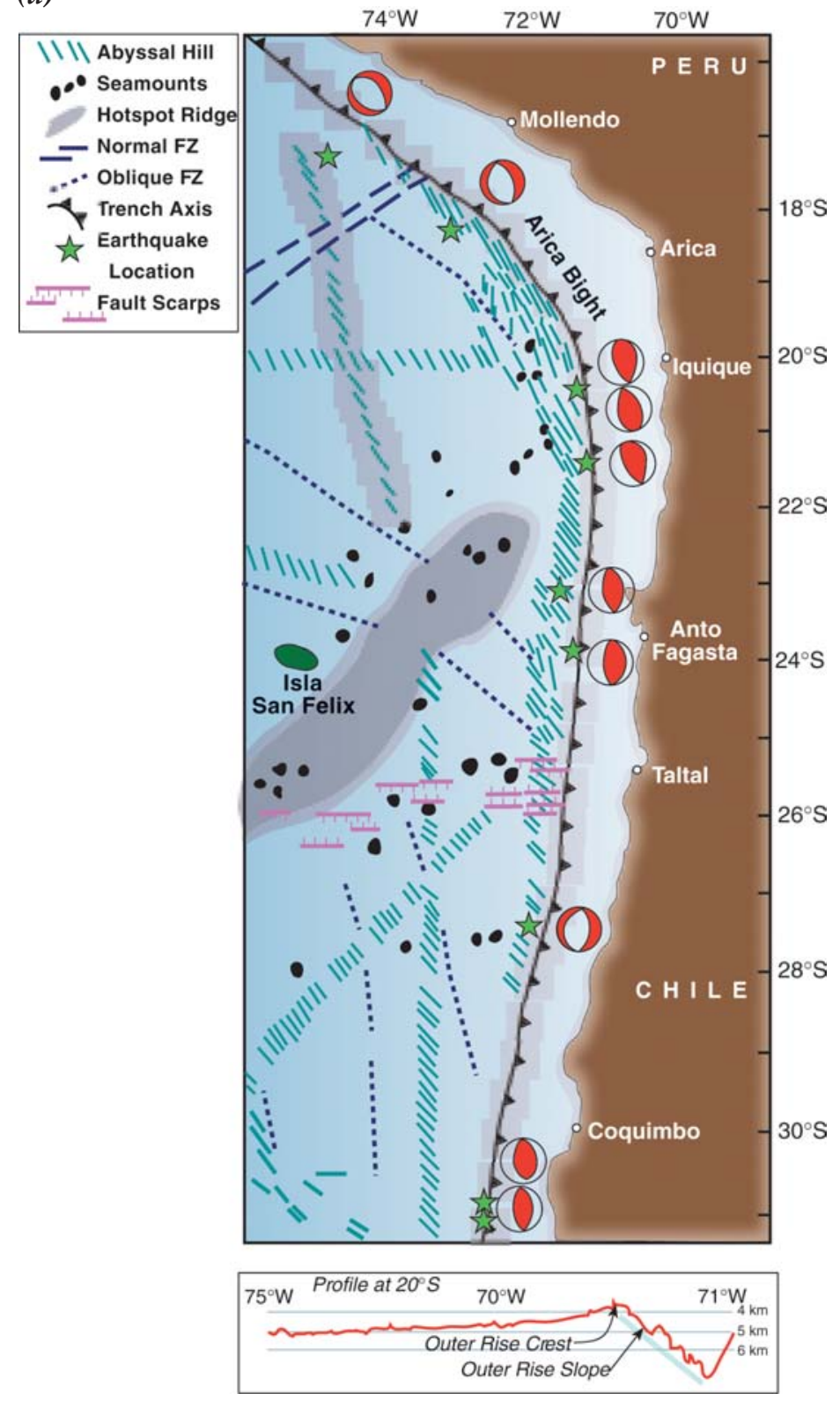

(b)

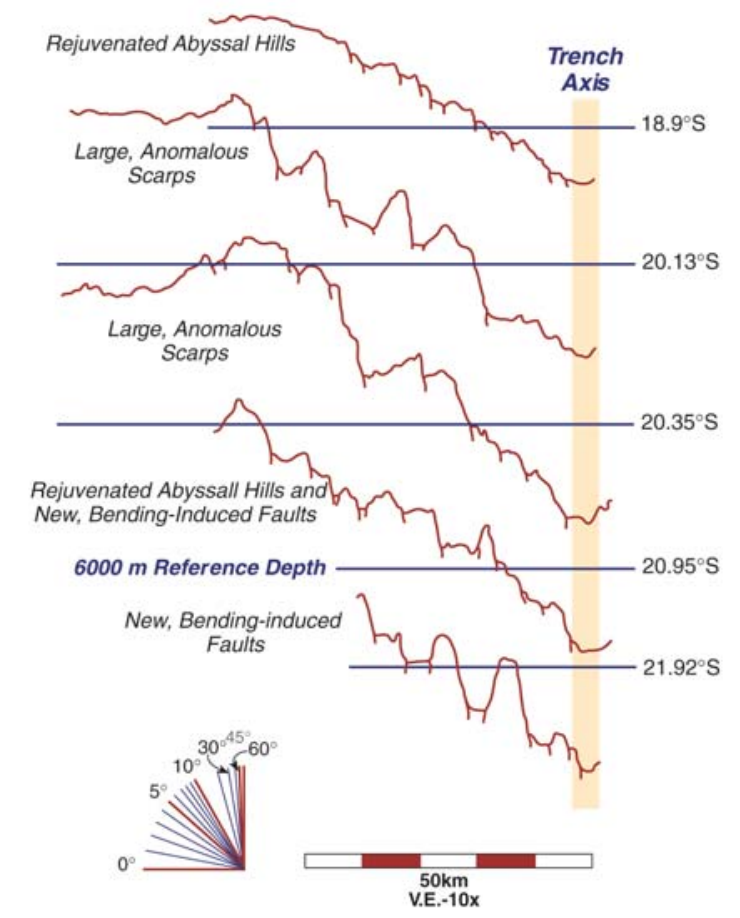

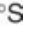

Figure 6. The orientation of abyssal hills on the ocean floor can help explain the potential for generating large fault scarps along the trench outer slope. The nature of these fault scarps may provide insight into the potential for earthquakes along the subduction zone. As a tectonic plate approaches a subduction zone at an ocean trench, it carries with it pre-existing faults inherited from the process that formed the abyssal hills on the sea floor when the plate was first generated by seafloor spreading. The process of subducting the plate bends it severely, requiring deformation that is accommodated by faulting. If the abyssal hills are oriented within $~ 30$ degrees of the trench, then the abyssal hill faults may be reactivated, limiting outer slope scarps to modest heights; if the orientation of old faults cannot accommodate the bending, then new faults break the seafloor crosscutting original abyssal hills. The relationship of these two fault styles to the potential for large magnitude earthquakes is under investigation. Both phenomena can be seen at the Peru-Chile Trench, where there is a large change in trench orientation and hence a change in fault type (rejuvenated abyssal hills vs. new, bending-induced faults). (a) Tectonic interpretation of the Peru-Chile Trench region. Stars mark the locations of seismic events on the outer slope; also shown is a bathymetric cross-section of the outer rise region at $20^{\circ} \mathrm{S}$. (b) Bathymetric profiles representative of the various faulting styles observed in outer rise regions, in particular the Peru-Chile Trench. Scarp height ranges from 100's of meters to larger than a kilometer along the Peru-Chile Trench. New faults scarps are consistently larger than rejuvenated abyssal hill scarps. The "large, anomalous scarps" coincide with the greatest change in trench axis orientation at the Arica Bight. 


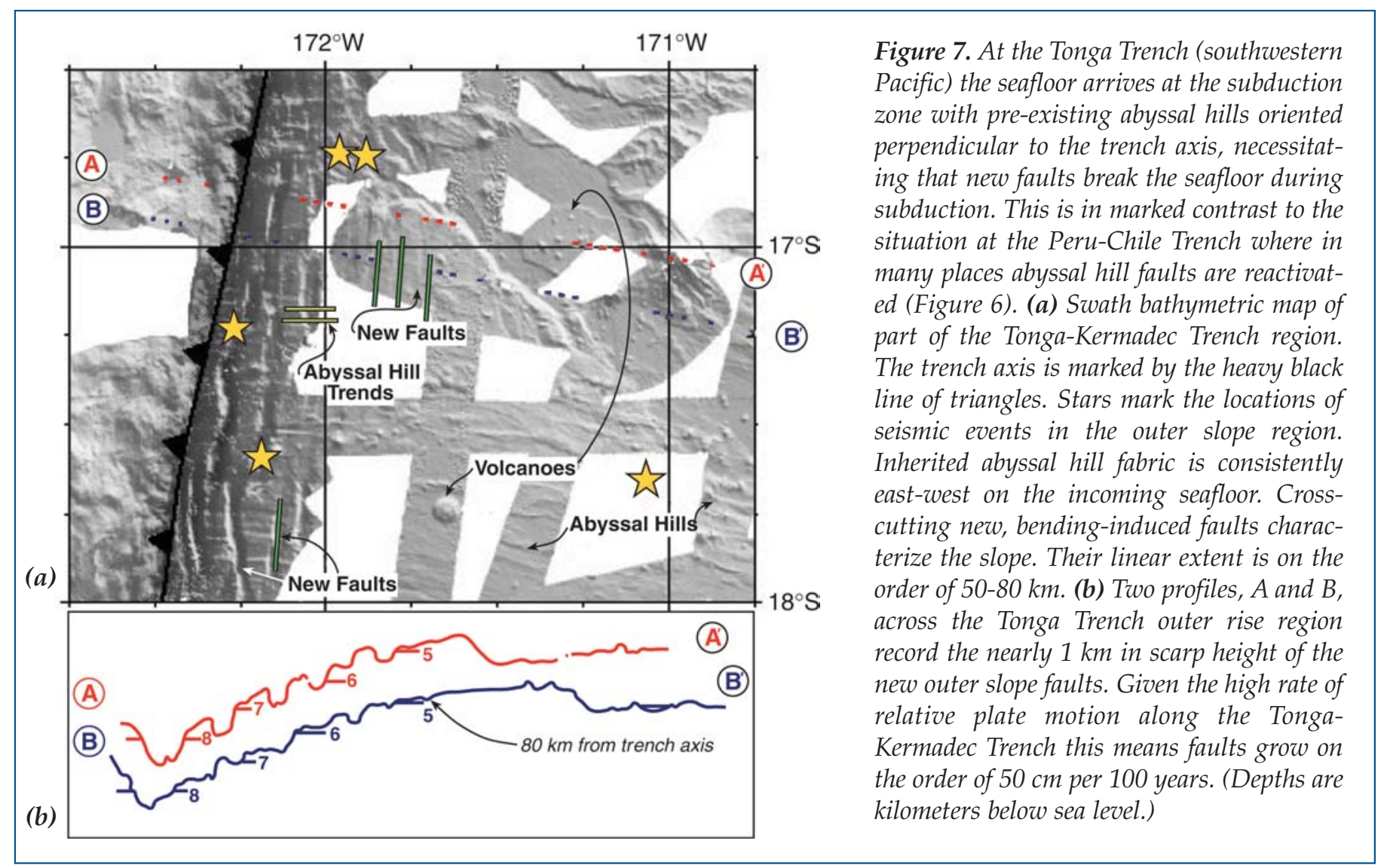

and $26^{\circ} \mathrm{S}$, five thrust events have been recorded. Four of them are located within $15 \mathrm{~km}$ of a major structural boundary or thrust block with which they may be associated. Thrust blocks identified on swath bathymetric maps cannot be attributed to compression with certainty because their plane of motion is coincident with that predicted for normal faulting. In contrast to the Peru-Chile Trench, 26 thrust events have been recorded on the outer slope and trench axis of the TongaKermadec Trench; yet none could be correlated with mapped bathymetric features.

The tectonic history of incoming seafloor can become very complex. Many factors complicate an otherwise straightforward characterization of the faulting on trench outer slopes. Whether outer slope faulting is a steady-state, continuous process or one that can be attributed to distinct, isolated seismic events is not well understood. The type of faulting observed is directly related to the inherited morphology of the seafloor prior to its arrival in the outer rise region. To better understand the bending-induced faulting on the outer slope the incoming seafloor must be well mapped and its tectonic history resolved.

\section{The Need for Improved Bathymetry From Space}

As the population of coastal areas increases the need for, and value of, scientific understanding of earthquake and tsunami hazards also increases. Simple maps of expected tsunami travel paths and times based on crude bathymetry have been of important operational value in developing a tsunami-warning infrastructure for some time. Bathymetry from Space (Smith and Sandwell, 1997) has revealed the global, deep seafloor topography in sufficient detail to allow the mapping of a Tsunami Scattering Index and to demonstrate that these scatterers can account for much of the geographic variability in tsunami amplitude. Future improvements will require still greater detail in bathymetry, particularly in continental shelf and slope regions that are the principal sources of trans-oceanic tsunamis and through which tsunamis propagate on their way to coastal impact sites. Establishing the minimum depths of seamounts and shallow areas around islands also will be needed. A future space bathymetry mission would improve the resolution of seamounts and other bottom features, and could reveal which areas merit more detailed acoustic surveys, resulting in great efficiency in survey resource deployment. A future mission, by revealing the orientation of abyssal hills and other small-scale features, might also contribute greatly to mapping and understanding the seismic and tsunamigenic potential of the seafloor near subduction zones.

\section{Acknowledgments}

The authors wish to thank W.H.F. Smith for his many helpful comments concerning this paper. The 
tsunami work was funded in part by the U.S. National Tsunami Hazard Mitigation Program to develop tsunami inundation maps for at-risk U.S. coastal communities and to improve the U.S. tsunami warning system. Information on these and other tsunami programs mentioned in this article can be found at the website http://tsunami.gov/, PMEL's website http://www. pmel.noaa.gov/ and the website of the International Tsunami Information Center http://www.prh.noaa. gov/pr/itic/. This publication is funded in part by the Joint Institute for the Study of the Atmosphere and Ocean (JISAO) under NOAA Cooperative Agreement No. NA17RJ1232, Contribution \#1042. Collection of bathymetric data along the Peru-Chile Trench and Tonga Trench was funded by the State of California and the National Science Foundation, respectively.

\section{References}

Chapple, W.M., and D.W. Forsyth, 1979: Earthquakes and bending of plates at trenches. J. Geophys. Res., 84(12), 6729-6749.

Christensen, D.H., and L.J. Ruff, 1988: Seismic coupling and outer rise earthquakes. J. Geophys. Res., 93(11), 13,421-13,444.

González, F.I., 1999: Tsunami! Sci. Am., 280(5), 56-65.

Massell, C.G., 2002: Large Scale Structural Variation of Trench Outer Slopes and Rises. Ph.D. thesis, University of California at San Diego, Scripps Institution of Oceanography.

Masson, D.G., 1991: Fault patterns on outer trench walls. Mar. Geophys. Res., 13, 209-225.

Mofjeld, H.O., V.V. Titov, F.I. González, and J.C. Newman, 2001: Tsunami scattering provinces in the Pacific Ocean. Geophys. Res. Lett., 28(2), 335-337.

Mueller, B., V. Wehrle, H. Zeyen, and K. Fuchs, 1996: Short-scale variations of tectonic regimes in the western European stress province north of the Alps and Pyrenees. Tectonophysics, 275(1-3), 199-219.

Smith, W.H.F., and D.T. Sandwell, 1997: Global sea floor topography from satellite altimetry and ship depth soundings. Science, 277, 1956-1962.

Stauder, W., 1968: Tensional character of earthquake foci beneath the Aleutian Trench with relation to sea-floor spreading. J Geophys. Res., 73(24), 76937701.

\section{Related Materials}

Bardet J.P., C.E. Synolakis, H.L. Davies, F. Imamura, and E.A. Okal, 2003: Landslide tsunamis: Recent findings and research directions. Pure Appl. Geophys., 160(10-11), 1793-1809.

Bernard, E.N., F.I. González, C. Meinig, and H.B. Milburn, 2001: Early detection and real-time reporting of deep-ocean tsunamis. In: Proceedings of the International Tsunami Symposium 2001 (ITS 2001) (on CD-rom), NTHMP Review Session, R-6, Seattle, WA, 7-10 August 2001, 97-108.
Bernard, E.N., and H.B. Milburn, 1991: Improved satellite-based emergency alerting system. J. Atmos. Ocean. Technol., 8(6), 879-883.

Bondevik, S., J. Mangerud, S. Dawson, A. Dawson, and O. Lohne, 2003: Recording-breaking height for 8000-year-old tsunami in the North Atlantic. EOS, 84(31), 289-293.

Koshimura, S., F. Imamura, and N. Shuto, 1999: Propagation of obliquely incident tsunamis on a slope, Part II Characteristics of on-ridge tsunamis. Coast. Eng. J., 41(2), 165-182.

Mofjeld, H.O., F.I. González, E.N. Bernard, and J.C. Newman, 2000: Forecasting the heights of later waves in Pacific-wide tsunamis. Nat. Hazards, 22, 71-89.

Mofjeld, H.O., F.I. González, and J.C. Newman, 1999: Tsunami prediction in U.S. coastal regions. In: Coastal Ocean Prediction, Coastal and Estuarine Studies 56, C. Mooers, ed., Chapter 14, American Geophysical Union, 353-375.

Mofjeld, H.O., V.V. Titov, F.I. González, and J.C. Newman, 2000: Analytic theory of tsunami wave scattering in the open ocean with application to the North Pacific Ocean. NOAA Tech. Memo. OAR PMEL-116 (NTIS PB2002-101562), 38 pp.

Tinti, S., E. Bortolucci, and A. Armigliato, 1999: Numerical simulation of the landslide-induced tsunami of 1988 on Vulcano Island, Italy. Bull. Volcanol., 61(1-2), 121-137.

Titov, V.V., F.I. González, H.O. Mofjeld, and J.C. Newman, 2001: Project SIFT (Short-term Inundation Forecasting for Tsunamis). In: Proceedings of the International Tsunami Symposium 2001 (ITS 2001) (on CD-rom), Session 7-2, Seattle, WA, 7-10 August 2001, 715-721.

Titov, V.V., B. Jaffe, F.I. González, and G. Gelfenbaum, 2001: Re-evaluating source mechanisms for the 1998 Papua New Guinea tsunami using revised slump estimates and sedimentation modeling. In: Proceedings of the International Tsunami Symposium 2001 (ITS 2001) (on CD-rom), Session 2-4, Seattle, WA, 7-10 August 2001, 389-395.

Titov, V.V., H.O. Mofjeld, F.I. González, and J.C. Newman, 2001: Offshore forecasting of Alaska tsunamis in Hawaii. In: Tsunami Research at the End of a Critical Decade, G.T. Hebenstreit, ed., Kluwer Academic Publishers, 75-90.

Watlington, R.A., W.D. Wilson, W.E. Johns, and C. Nelson, 2002: Updated bathymetric survey of Kick'em-Jenny submarine volcano. Mar. Geophys. Res., 23(3), 271-276. 